\title{
Understanding self through difficult family dynamics and cultural appropriation
}

\author{
Atsuko Kawakami ${ }^{1}{ }^{*}$, Lidia Madeleina Gorman ${ }^{2}$, Jensen Elise Branscombe ${ }^{3}$ \\ 1, 2, 3 Department of History, Sociology, and Geography/GIS, Tarleton State University, Stephenville, TX
}

\section{Keywords \\ Cultural appropriation \\ Peruvian medicines \\ Family dynamics \\ Identity}

Received: 4 September 2019

Accepted: 14 November 2019

Published: 12 March 2020

\begin{abstract}
This paper originated with a question about cultural appropriation by westerners of indigenous Peruvian medicines and cultural practices. It has developed into a collaborative, self-reflexive project between one of the authors of this paper and her academic advisor. Her father, a journalist, and adventurer has organized regular tours through the Amazon that focus on practicing and experiencing Peruvian medicine. He has had a lifelong desire for an adventure that led him into the deep jungles of Peru. While his research and exploration have led to "selfdiscovery and contributions to science," his travels left his daughter with a sense of discomfort and concern. After his return to the United States, her father shared his new knowledge of Amazonian medicines with the Western world through published accounts of his travels as a daughter of a white American father and a Peruvian mother, one of the authors of this paper started to question her father's actions and wondered if they would be considered exploitation and illegitimate exportation of indigenous medicinal culture. By using a combination of content analysis, case study, and collaborative autoethnography supported by our self-reflexive journal writing, this qualitative study explores the possibility and limitation of academic discourse and the etic and emic perspectives to guide someone to have a better understanding of "self" and family relations within a unique set of Peruvian medicines and practices in western society.
\end{abstract}

(C) 2020 TAF Publishing. All rights reserved.

\section{PROLOGUE}

"My father came upon a different culture's practices and gained some sort of (according to him) incredible knowledge. He shares what he knows with other people, hopefully giving them the same opportunity he had. . . I just know that the older I get the more I question my father's privilege, and why he thought he had a right to share what he found. Like an explorer finding the "New World" (Madeleina Gorman, personal notes, Feb. 19, 2020).

"I worry that the domino effect that has occurred after my father's 1984 trip may have done a lot of harm . . Peruvians are selling their culture. Other groups may have tried to claim Matses [indigenous people of the Amazon] cultural practices. Westerners are getting hurt because some Peruvians are lying to them about these practices, and damage is happening to that part of Peru, specifically the Amazon, in the name of this tourism. I don't think that I can justify some people having an incredible experience for all of that. But I'm only half Peruvian, and I don't live down there, so I don't know if it is my place to say how much it has hurt or helped that community" (Madeleina Gorman, personal notes, Feb. 19, 2020).

\section{INTRODUCTION}

In Peruvian indigenous culture, many illnesses, ailments, or even bad luck are considered physical symptoms of disturbances on spiritual planes (Fotiou, 2012). Because these symptoms are caused on an external level, traditional Peruvian culture dictates that the solution must be found or understood on the same external level (ibid). Plant-based teas like ayahuasca are used as "teachers" by the curanderos, or the healers/shamans, to help find the answer to their patients' problems (Luna, 1984). Ayahuasca is an herbal tea brewed from the Banisterioopis Caapi vine and other

${ }^{*}$ corresponding author: Atsuko Kawakami

†email: kawakami@tarleton.edu 
plants that contain the hallucinogen dimethyltryptamine (Dobkin \& Grob, 2005). This tea is prepared by a curandero (Kavenská \& Simonová, 2015).

Typically, to become a curandero, one must study under another curandero, become familiar with the medicinal plants, and spend isolated time in the jungle (Kavenská \& Simonová, 2015). Once a student has earned the title of curandero, he or she can start receiving clients who come to ask the curandero to "look" at what is ailing them or ask him/her to have "visions" of who is causing them the problems (Dobkin \& Grob, 2005). While sometimes these clients may personally participate in these rituals, the medicine is usually only taken by the healer (ibid). This is performed in a ceremony where the curandero drinks the brew, typically using mapachos (cigarettes rolled with black smoking tobacco), agua florida (floral water), alcanfor (camphor), and icaros (songs/melodies), to aid and protect them throughout their spiritual journey to find the source of their client's problems (Fotiou, 2012; Luna, 1984). Then, the curandero handles or removes the negative spirits causing problems or informs the client what changes need to be made so that they may fix those problems (Fotiou, 2012).

It is not uncommon for the healer and the client to "see" the same vision when the curandero is "working" on someone during the ayahuasca ceremonies. For example, one of the subjects of this paper, Gorman (2010a) claims the curandero, the client, and Gorman himself "saw" a vision of the client's wife speaking to a priest, writing "... all of us saw the same thing" (p.17), meaning that that the three men shared the same vision. Other times, Gorman talks about "seeing things" that are happening in other parts of the world in real time under the influence of ayahuasca. On one occasion, during an ayahuasca ceremony in Peru, Gorman had a vison that his friends (who had sublet his New York apartment) had rearranged the furniture. When he returned to New York, the furniture had indeed been rearranged and an astonished Gorman (2010a) (p.33) reflects, "And what of the apparent astral traveling I'd done to ... New York?" Many westerners travel down to Peru and other parts of South America so that they may try this medicine directly (Kavenská \& Simonová, 2015). These tourists, who are looking to find a way to help heal their spirit, seek out the curanderos who may brew and serve ayahuasca to them in their own ceremony (Fotiou, 2012). This trend has led to many unqualified or underqualified healers serving the medicine to tourists for the sake of business rather than for the sake of healing (Kavenská \& Simonová, 2015). These non-traditional healings have led to upset amongst the natives as well as injuries and even unintentional death to these westerners (ibid).

At the same time, many western medical practitioners and pharmaceutical companies have marketed indigenous people's knowledge about natural herbs and plants for personal gain and profit without giving credit to indigenous people or acknowledging the sacred spiritual nature of traditional ayahuasca practice (George, 2010; Trichter, 2010). Western tourists have reported that they experienced boosted moods and increased awareness of themselves and the spiritual world through hallucinations they have after drinking the tea (Re, Palma, Martins, \& Simões, 2016). Gertner (2019) describes one of the main problems at the root of cultural appropriation is that when certain symbols or styles specific to a culture are sold as some form of merchandise to a different culture, the result is that the original culture is reduced down to only those few recognizable symbols or styles. The significance of those symbols may have then been "watered down" and are no longer truly representative of that culture (Gertner, 2019). In this case, not only are western companies profiting from ayahuasca, many of the people using the tea are profiting from it without a curandero. Sometimes, those who are knowingly or unknowingly participating in cultural appropriation do so with the assistance of unwitting helpers. Such a person is the subject of this paper, and is also the second author. The second author is a daughter of a Peruvian mother and a white American father. She has assisted in many ayahuasca ceremonies and has been deeply involved in Peruvian culture while she grew up in the United States and Peru. Intense debates over cultural appropriation can be observed on social media platforms. Biracial and multiracial individuals who share their thoughts on such public platforms often have particularly insightful points of view as they frequently feel that they are simultaneously "insiders" and "outsiders" of particular minority cultures. Popular magazine articles also introduce biracial or multiracial individuals' views on how appropriate it is for the dominant group to adopt the minority groups' cultural practices such as their food, art, fashion, or hairstyles (Chambers, 2018; Murtagh, 2018). Those biracial and multiracial individuals are practicing self-reflexivity when they reflect on this "insider-outsider" position, though they do not use this particular academic term.

Self-reflexivity occurs when an individual looks at oneself in order to recognize what biases his/her social conditioning has developed within him/her (Farrugia, 2013). Farrugia (2015) points out two possible evaluations of selfreflexivity when it is used in research, on the one hand, once an individual realizes what their biases are, he/she be- 
comes liberated from those biases. Therefore, his/her research is freed from, or at least less affected by, bias. On the other hand, since social conditioning is based on the complex web of social relationships and social structures, selfreflexivity alone cannot pronounce one's research unbiased (ibid). Self-reflexivity, then, may not guarantee bias-free research results. When it is used in combination with an etic and emic analysis of cultural practices, however, individuals may have a better understanding of themselves and their surrounding conditions and environments.

Nelson (2004) uses journal writing as the tool of "being" and explains how one's journal can be transformed to something new and meaningful to be shared with others. Guided by this approach, we will display the process of combining our emic and etic views on ayahuasca practice and its effect on a racially mixed family by using our self-reflexivity and journal notes. It is our hope that this collaborative writing will help others to evaluate their personal choices or ponder the effect of academic practice in advising at educational entities.

\section{Background of this Study}

The first author is the academic advisor of the second author, who is an undergraduate sociology major student. The second author started to visit the first author's office frequently for academic advice. Soon, the conversation became the second author's unique ayahuasca experiences and Peruvian background as well as life in general. As the advisor, the first author felt some of the stories the second author shared were concerning and did not know the best way to advise her. Some of the issues the second author raised were doubt about her future as a college student, the uncertainty of her identity, and her life in general. For that reason, the first author suggested the use of academic discourse as a tool to figure out what the second author wants to do in her life by discovering who she is. Since the first author is not a licensed clinical psychologist or counselor, nor the second author a client or patient, we had no intention to diagnose or conduct therapy sessions. Rather, we decided to produce a self-reflexive paper together to organize our scattered thoughts on cultural appropriation, identity, and future planning.

The second author's father is a journalist and adventurer who has organized regular tours through the Amazon that focus on practicing and experiencing Peruvian medicine like ayahuasca. He has had a lifelong desire for adventure which led him into the deep jungles of Peru. While his research and exploration has led to "self-discovery and contributions to science" (Gorman, 2010a) (p.60), his travels left his daugh- ter, the second author, with a sense of discomfort and concern. After his return to the United States, her father shared his new knowledge of Amazonian medicines with the western world through published accounts of his travels. While he is not the only person to engage in such acts, his daughter started to question her father's actions and wondered if they would be considered cultural appropriation. Additionally, his body has endured many trials from his trips to the Amazon causing various physical problems. In his attempt to alleviate the detrimental effects of his travels, he uses his daughter to help him process his experiences as well as for other personal and business assistance. The connection she has forged with her father during these conversations and having to bear the burden of his emotions is so deep that she believes that she may die when he does.

Schlosser, Lyons, Talleyrand, Kim, and Johnson (2007) reviewed effective mentorship with advisors and advisees in graduate school and maintained the idea of advising holistically, which includes consideration of "personality; racial identity status; levels of acculturation, enculturation, and cultural mistrust; gender roles; [and] work style preferences... to tailor interactions with a particular student" (p.47). This concept seems relevant for not only the graduate school setting, but also for the undergraduate setting when seeking an effective mentorship. That is how we decided to explore the question of how academic discourse can (or cannot) guide an individual to have a better understanding of self, family dynamics, and plans for the future.

\section{METHODOLOGY}

In order to carry out our project, we reviewed publications of the second author's father, which mostly describe Peruvian Amazonian medical and cultural practices. These publications include his self-published books and blog articles. No consent or the Institutional Review Board's approval was needed since the data was publicly available. We used latent content analysis, rather than manifest content analysis when we evaluated the publications. In that way, the significance of the postings or writing was not determined by the frequency of usage with a specific term or vocabulary. The first and second authors discussed and documented their own thoughts about the books and blog articles. Because the first and second authors were already closely involved with this research topic, the third author took the role of providing an outsider's point of view of both the advisor/advisee relationship and of the second author's family dynamics.

Following Ratner (2002) observation that qualitative research methods recognize researchers' subjectivity and 
how they can use their subjectivity as a tool when choosing a topic, formulating a hypothesis, selecting a methodology, and interpreting data, we have utilized our subjective judgment to identify the themes of Gorman's blog articles and the parts of his book we consider significant. To critically and creatively interpret what we read, we used our own self-reflexive notes to expand our thoughts. We understood the limitation of self-reflexivity as D'Arcangelis (2018) recognized that self-reflection does not necessarily take away researcher's privilege and biases whilst conducting research; however we also saw Nelson (2004) (p.26) pointed out "writing was, in itself, a way to discover things about [oneself] and the world." We understood that even though individual researchers may struggle with selfreflexivity, there may be value in attempting to apply it to specific fields of study or certain qualitative methodologies, as Neill (2006) mentioned. In this way, the method we used for this project was a combination of content analysis, case study, and collaborative autoethnography supported by our self-reflexive journal writing. With these understandings, we will start our analysis with Peter Gorman's publications followed by our discourse.

\section{ANALYSIS}

Etic Reflections: Identity and Family Business of Peruvian Medicine Dreaming

From the readings and numerous hours of conversation with the second author, the first author and the third author understand that the ayahuasca ritual is a combination of hallucinogenic medicine, psychic reading, and spiritual advice, which allows the healers and patients to be fused together on a spiritual plane to seek the solution for the problems or issues together. This view of ayahuasca practice became an important concept for us to recognize the second author's understanding of herself. The second author spends a considerable amount of time supporting her father's ayahuasca tourism business and his health. It often interferes with her school work, but taking care of her father is a central part of her life and has become a central part of her identity. Her father's writing includes examples of how hard his daughter works. He wrote the following in his blog:

"...four guests who are coming Sunday afternoon...Madeleina is finishing up [cleaning] the big living room right now...Madeleina is doing much more than I am...I don't think Madeleina and I would be happy if we didn't have some fantastically impossible chores to do in a minimal amount of time" (Gorman, 2015) (paragraphs 3-5).
While we were working on this project, the second author's father had to come back early from his Amazon tour due to his medical condition.

"...Were it not for me last year, my dad would be dead. He almost died again this time. If he goes, then so do I. This is the exact situation I've been preparing for" (Madeleina Gorman, personal notes, Feb. 26, 2020).

Although the situation described above is resolved now, the first author started to wonder if the Amazon medical tourism and ayahuasca itself are actually helping or hurting the second author's father's health. The second author wrote:

"Ayahuasca gave him tools, but he is still a giant fuck up, so he still messes up. Jungle medicine isn't the answer to all of your problems, it just offers a different way of looking at them .... If the man did not take the advice and kept getting hurt, that wouldn't be the medicine's fault. It already did its job, after that it was up to the man to make the changes himself. My dad still messes up, but that is not ayahuasca's fault. It already did its job" (Madeleina Gorman, personal notes, Feb. 23, 2020).

The ayahuasca medicine dream practice seems to hold the key to understanding the interpretation of the second author's life. The first author and the third author understood that genuine ayahuasca practice requires that the boundary between the healers and patients be removed as the healers drink ayahuasca, in order to see the cause of client's problems (Apud \& Romaní, 2017). We saw an infused collective identity within the practice of ayahuasca medicine dreaming in this family's dynamics.

We also wondered if the concepts of cultural appropriation within ayahuasca practice can be applied to this family's dynamics. Many scholars have warned the physical harm due to the misusage of Amazon medicine by westerners as well as cultural appropriation of the medicine to gain financially for themselves. The first author wrote in her self-reflection notes:

"A western man owns an Amazon tourism business and practices ayahuasca medicine in a western society with a great deal of his biracial daughter's time and effort. It can be understood as a form of cultural appropriation. It could be considered the individual level of cultural appropriation within the family since the daughter's time and emotional work are seen as readily available for him .... At the same time, because of this business, he can pay bills for his daughter ... The conundrum here is that the daughter holds a critical view toward cultural appropriation of Amazon culture and practices by the western societies at the macro level; however, she does not see the same principle within her own family. She does 
not see herself as being taken advantage of. She does not see herself as an individual who needs her own time to build her own life. She has a total acceptance of her life that revolves around her father" (Atsuko Kawakami, personal notes, Feb. 28,2020 ).

Interestingly, the father of the second author is well aware of cultural appropriation of Peruvian medicine.

"Many healers now have several apprentices where just five years ago they had none. Next, there is also the negative of westerners coming back from indigenous or mestizo areas of Central and South America thinking they have shamanic knowledge and trying to pass it on when they have learned nothing ..." (Gorman, 2010c) (paragraph 10).

He even mentions that the indigenous curandero "might no longer have time to tend to their needs now that he or she is in such demand by westerners" which "can throw off the balance of whole communities" (Gorman, 2010c) (paragraph 9). He expresses his self-reflection and sincere concern about his role, which might have had negative effects after introducing ayahuasca practice to westerners.

"There really is no going back. I was certainly one of the first to talk about ayahuasca use in Peru ... in a national magazine about ayahuasca, and I've had to live with whether that was a good or bad thing ever since" (Gorman, 2010c) (paragraph 11).

Yet, how cultural appropriation is affecting the family seems to be unrecognized.

\section{Etic Reflections: Gender and Family Dynamics}

There also seems to be a gender dynamic in the relationship between the second author and her father. (Gorman, 2007) (paragraph 2) describes his Peruvian medicine tour as "hopelessly male-oriented." All of us recognize his masculinity and general patterns of high risk behaviors such as smoking and excessive drinking (Gorman, 2010a), avoiding medical attention (Gorman, 2019) (paragraph 1), and preferring a physically adventurous life (Gorman, 2010a)(p.41). For example, he mentions in his blog that even his friends are concerned with his addictions: "a friend ... pointed out that with the wine I drink and the number of cigarettes I smoke, it's up to me to either change or die" (Gorman, 2018a) (paragraph 1). Gorman (2010a) also mentions that he has had problems maintaining his sobriety, even though Gorman's ayahuasca visions warned him "... you will still have to finally quit [smoking] if you want to live" (p. 197) and advised that he "[d]rink less, write more" (Gorman, 2010a) (p.16).

As an outside observer of this family, after reading the second author's self-reflexive notes, the first author wondered if the family was "doing gender" or if there was a codependent relationship between the father and daughter. The second author recognizes multiple dimensions of her father as he expresses his support for women's rights and gender equality in his blog (Gorman, 2018b) (paragraph 1) as well as his loving attitudes toward his family and friends, yet she also sees how he expects his daughter to help his business and his health while overextending himself to care for everyone else. As the outsiders of the family and as academics, the first author and third author had to selfexamine whether we were unfairly judging this father's behaviors as a typical pattern of male chauvinism as his actions do not seem to support what he writes. We also wonder if we were falling into the trap of essentializing a person into a one-dimensional character or if we were trapped into stereotypical interpretation of the situation using wellestablished academic concepts. As such, the first author wrote her self-reflexive notes on how the academic advising had been helping or not helping the second author.

"Is this some form of doing-gender or codependency? ... I remember when I asked what she wants to do after graduating college, she became emotional and said she doesn't know. She told me that it bothers her that all of her teachers in high school and advisors in college have been asking the same question. I told her that it is OK if she doesn't know at this moment, that's why an internship project is required in the senior year to find out what students would like to do .... I suggested to her that we can find out who she is and what she wants to do together by conducting research about Amazon medical practice in western society for her internship project. But now I am thinking my advice might have been too goal-oriented or was imposing on her to conform to the well-established pathway for college students, which may not fit in her cultural and personal backgrounds" (Atsuko Kawakami, personal notes, Feb. 24, 2020).

\section{Emic Reflections: Ayahuasca, Self-Identity, and Family Dynamics}

The second author acknowledges the role ayahuasca has played in shaping who her father is. A lasting "lesson" from one of Gorman's visions came in the form of the phrase "More Joy, Less Pain" (Gorman, 2010a) (p.175). To this day Gorman continues the practice of trying to create more joy and eliminate pain in his daily life and believes that implementing this lesson is what has helped his family "heal" (p.176). As such, he wrote:

"Once, years ago, I was in an ayahuasca dream and asked the spirits what I could do to make a better living as a writer. Without hesitation a spirit said: 'Drink less. Write more.' 
That was it. The whole answer. So I drank less, wrote more and pretty soon was able to support my family on investigative journalism" (Gorman, 2006) (paragraph 28).

The second author wrote the following reflection on her father's writing about the revelations he had while participating in an ayahuasca ritual:

"The 'messages' that my father has received help shape the person he is now. He doesn't take those lessons lightly... he is not perfect, and he fails sometimes, but those lessons of drinking less, writing more, and causing less pain are what have helped our family not rip apart further" (Madeleina Gorman, personal notes, Feb. 22, 2020).

Reflecting on how hard she works to support her father's business, the second author thinks that her father probably has no idea how much he depends on her. Her self-reflective notes indicate her frustration and appreciation for her father simultaneously.

"This is an example of me directly having to prepare for these guests. My entire life people have been coming in and out of my home, and it has always been my job to help accommodate my father's guests when they come. What he doesn't mention ... is ... that it's my job to watch those 13 people during the ceremony. I watch after them when they take medicine" (Madeleina Gorman, personal notes, Feb. 25, 2020).

"... I am exhausted because I always have to take care of my dad, [but] even though I am always worried, I get to live a special life because of him. He makes me angry, and he can be a jerk, but he's smart and funny and kind, and because of him I have gone to the jungle, I have met some of the most incredible people in the world, and have lived a life full of support and love. Once he's gone, that all goes away. He's the connection to the magic, and without him I'll lose my best friend and all of the wonder that comes with being his child" (Madeleina Gorman, personal notes, Feb. 26, 2020).

Her selfless support for the father was reciprocated by him. Her single father posted his love, joy, and excitement on his blog while preparing his house for his children to visit him. "All I can do is say THANKS, GOD, for bringing these crazy creatures into my life!!!!! What little price it is to pay to have to spend an hour cleaning up for every hour they are here? That's nothing!!!!" (Gorman, 2010b) (paragraph 10).

Despite his joy of seeing his children, his two older sons seem to be less attached than his daughter, the youngest of all.

"...He is always upset when [his two sons] haven't come to visit him in a while, and he always looks the most [upset] when they say they're going to come over and then change their minds .... My older brothers didn't really spend time with my father when he would go into those moods, so it was up to me to sit with him when he cried ..." (Madeleina Gorman, personal notes, Feb. 22, 2020).

The daughter, the second author, visits him every weekend and even on weekdays. To take care of him, she has to miss class frequently. The second author has experienced many contradictory feelings about her father, especially during his times of need. Those times of need became more frequent after she started attending university. Her father's needs are both physical and emotional.

"After I started school he would call almost every day.... He would be disappointed or even get upset if I couldn't come home on the weekend. He would even get jealous of my boyfriend because I would come home on the weekend and spend time with him [instead] .... When I was a sophomore and junior I really resented my father. I was so mad that he wanted so much of my time when my whole life had already been dedicated to looking after him. Things are better though, I have gone back to being his favorite and looking after him. Dad was who I had, who I could count on. We took care of each other, we are each other's favorites, and each other's best friends. I never made a plan to leave my dad .... I realize though, that my life has no meaning beyond assisting my dad" (Madeleina Gorman, personal notes, Feb. 19, 2020).

While the second author's father may have not have fully understood the strain he put on the relationship, the second author recalls those first few years in college were immensely stressful. The second author now recognizes that those experiences may be part of the reason she would not be comfortable becoming more independent from her father, as she has already seen the negative toll that that separation could take on him.

The second author accepts a limited role that gender plays in her family dynamics. She sees her father's tendency to act "tough" or show a brave face in situations where he may feel vulnerable, traits traditionally associated with masculinity. He often takes pride in being the head of his household and usually takes on the social expectations attached to that role, such as not wanting to appear weak, overextending himself so that he can take care of everyone, and not wanting to admit he may need medical attention. He is generally a skeptic of western medical care, rooted in his childhood experiences, as he wrote "...my reluctance to go to the hospital ... I hate going ... because it feels like prison" (Gorman, 2019) (paragraph 2). This, combined with his confidence in Amazonian medicine (Gorman, 2010a), means the often refuses to seek medical attention in the United States (Gorman, 2019) (paragraph 2). As his daughter, the second author has to convince him to seek the care he needs. 
"[A family friend] and I spent the entire night trying to convince him to go to the doctor. After that we spent hours and hours in the emergency room, and took shifts watching after him in the ICU. If we had not almost forced him to go to the doctor, and then almost forced him to go to the emergency room, he would have died "(Madeleina Gorman, personal notes, Feb. 23, 2020).

The second author was already keenly aware of the concepts of "doing gender" and co-dependency. She even mentions empty-nest syndrome in her notes to describe how her situation may appear to others, though she denies that she is in that situation at all.

"I don't mean to come off as one of those house wives that slaved away to take care of her kids, and now that they have moved out, she is unsure of her purpose. That woman had at least some choice. That woman grew into being a mom. I was born into being my dad's sidekick. Who else was going to take care of him? Who was going to take care of me? My brothers were older and were always looking for a way to get out, to get away ..." (Madeleina Gorman, personal notes, Feb. 25, 2020).

\section{What Comes Out from Etic and Emic Reflections}

After so many hours of discussions on cultural appropriation, gender roles, and codependency, the first author finally offered her etic view of this family dynamic to the second author and asked: Is this the micro level of cultural appropriation within the family supported by the mechanism of developing a fused identity through ayahuasca? This may not be actual cultural appropriation as it is commonly understood, but is it still a form of taking advantage of a culture that is not one's own? Is this action supported by the second author?

The second author was also asked why it is okay for her to be "a sidekick" of her father and why it is okay not to have her own life. She did not have a clear answer at first. Then, a few days later, she wrote in her notes:

"... you must understand how I view myself and my life. My father has lived the richest and most interesting life that perhaps anyone has ever lived. It is because of this example that I have grown up with that I have commitment issues. I fear that if I choose a single path in life or decide to put all my efforts into only a few of my interests, I will miss out on all of the opportunities that life has to offer .... In ayahuasca healing, there are solutions offered up, but most of them must be done by the person wanting to heal. This medicine is not just like Advil that takes the pain away, it makes you confrontyour fears and desires and your past. But if she [ayahuasca] gives you an answer, it is you that must still do the work to "fix" yourself. If you choose not to take ayahuasca's advice, then you may not get out of it what you were hoping. In that way, I am refusing ayahuasca's advice. I know that I am scared of change and commitment, but I don't intend to face those problems. I have found the solutions, but now it is up to me to actually try to "fix" myself. But I am too scared to. That is why I let my father use so much of my attention .... It allows me to avoid the reality that if I live once he has passed, I will have to face my fears" (Madeleina Gorman, personal notes, Feb. 29, 2020).

From the view of an insider of the family that practices ayahuasca, the second author's identity was built on her refusal of ayahuasca's advice rather than the micro level of cultural misuse of ayahuasca by her Caucasian father. It was not codependency either. It is her active and conscious choice of not facing problems at this moment. The second author realizes that she is perhaps mirroring her father; she is trying to distance herself from situations in which she may feel vulnerable or weak. By avoiding the reality of adulthood and decision-making, similar to her father avoiding hospitals, she also avoids the fear that comes with responsibility and change. By maintaining the "sidekick" role, the second author may feel more secure in herself and her life, regardless of the more burdensome parts of her and her father's relationship.

\section{DISCUSSION}

The etic view and emic view show very different pictures of this issue and offer different understanding and explanation. Bergman and Lindgren (2018) explain that a successful integrative emic-etic perspective requires a trustful relationship between the insiders and the researchers, a reflexive approach to this relationship to maintain a balance between getting close enough but not to lose critical distance. Schlosser et al. (2007) summarized effective advising which necessitates the ability to guide an advisee's growth without imposing an advisor's own worldview by assessing 'the advisees' strengths and limitations and provid[ing] constructive feedback to students in an open, honest, and empathic way" (p.47). As an advisor who learned the advisee's cultural and family backgrounds, encouraging her to be more independent and find her own career goal does not settle well with the first author as it insinuates the idea of individualism or a career-oriented mindset as a "better" approach than having a collectivistic approach to life or focusing on the spiritual side of life. From the emic view of each student's unique background, advisors have to learn who the advisees are and how to offer different pathways to find out what they want to do, rather than imposing a well- 
established world view. As long as an advisee's life is not in danger physically or emotionally, it may be necessary for advisors to actively choose not to give any advice but just to encourage writing until the advisees find out what they are looking for, even if it takes extra time or a few detours. Nelson (2004) saw writing as a way of "being" in which healing one's past, claiming his/her present, and transforming his/her future. He was taught to write when he had something worthy to say which resulted in writing rarely. Now, as he describes, "I write in my journal to find out what I have to say-so I am forever writing" Nelson (2004) (p.26). In a sense, the ayahuasca advice that the second author's father received years ago, "write more" (Gorman, 2010a) (p.16), can be used as a more broadly applied therapeutic tool. In the case of the second author, the opportunity to do research related to her personal dilemmas turned out to be tremendously helpful. The researching process was indeed instructive and allowed the author to realize quite a bit about herself that she had not clearly understood before. She was comforted by the fact that other writers had similar difficulties with biracial and multicultural experiences. After having a clearer understanding of her own reasoning and decisions, the second author discussed her findings with her father, something she would have tried to avoid in the past.

As one can see from this case study, advisees are benefited by self-reflexivity and integrating an advisor's etic view into their own understanding. If the etic view that is offered by an advisor does not feel quite right or accurate in their particular situation, then advisees are forced to develop their own emic view of self-identity within their own cultural practices. This proved to be true for the second author. When the advice she received from the first author did not perfectly fit into the second author's vision for her future, she felt that it was not only important, but necessary, to solidify her sense of self and understanding. While the second author may not be entirely convinced that her path forward exactly matches her mentor's, her new found knowledge and appreciation for cultural impact and the influence (or lack thereof) between micro- and macro-level relationships has allowed her to have a better understanding of herself and her actions. In this sense, we have followed Bergman and Lindgren (2018) process of integrating emic-etic perspective by bringing researchers' and participants' perspectives together in the final stage of the process.

\section{CONCLUSION}

We have utilized our self-reflection to discuss how one's self identity is built and interpreted in the context of cultural appropriation of ayahuasca practice. Our etic view and emic view indicate very different understandings of the issue. Our academic discourse helped us realize the importance of mixing emic and etic perspectives to avoid imposing the well-established pathways or culturally accepted goals onto an individual who might have a very different cultural background. However, how much of this understanding of selfidentity or academic practices of journal writing and selfreflexivity would help to find one's pathway in the actual sense remains unclear. While the results of this study may not necessarily be that the advisee can find an entirely new vision for the future, it is clear that useful and helpful developments can be made. Attempting self-reflexivity and realizing its shortcomings, exploring other cases similar to one's situation, and being confronted with an etic view that differs from one's own view, have allowed an advisee to be a better researcher. One's strengthened skills in research and his/her trust in personal discussion with his/her mentor, while not entirely changing one's mind, allow the individual to observe other interpretations of his/her life. Thus it causes the individual to be at least somewhat more thoughtful when considering his/her own path, even if that does not mean creating an entirely new one.

\section{LIMITATIONS AND RECOMMENDATIONS}

The purpose of this paper was to understand whether academic discourse can help to find one's identity collectively within the scope of cultural specificity. Therefore, this paper did not intend to diagnose an individual's psychological wellbeing or discuss how healthy it is to understand one's identity within the context of cultural appropriation. Further study is needed with psychological approach for the purpose of counseling practice.

\section{REFERENCES}

Apud, I., \& Romaní, O. (2017). Medicine, religion and ayahuasca in Catalonia: Considering ayahuasca networks from a medical anthropology perspective. International Journal of Drug Policy, 39, 28-36. doi:https://doi.org/10.1016/ j.drugpo.2016.07.011

Bergman, Å., \& Lindgren, M. (2018). Navigating between an emic and an etic approach in ethnographic research: Crucial aspects and strategies when communicating critical results to participants. Ethnography and Education, 13(4), 477-489. doi:https://doi.org/10.1080/17457823.2017.1387066 
Chambers, G. (2018). How being biracial makes me feel about cultural appropriation. Retrieved from https://bit.1y/ $3 g 7 v I q r$

D’Arcangelis, C. L. (2018). Revelations of a white settler woman scholar-activist: The fraught promise of self-reflexivity. Sage Publications, 18(5), 339-353. doi:https://doi.org/10.1177/1532708617750675

Dobkin, D. R. M., \& Grob, C. S. (2005). Editors' introduction: Ayahuasca use in cross-cultural perspective. Journal of Psychoactive Drugs, 37(2), 119-121.

Farrugia, D. (2013). The reflexive subject: Towards a theory of reflexivity as practical intelligibility. Current Sociology, 61(3), 283-300. doi:https://doi.org/10.1177/0011392113478713

Farrugia, D. (2015). Addressing the problem of reflexivity in theories of reflexive modernisation: Subjectivity and structural contradiction. Journal of Sociology, 51(4), 872-886. doi:https://doi.org/10.1177/1440783313480396

Fotiou, E. (2012). Working with "Lam edicina": Elements of healing in contemporary Ayahuasca rituals. Anthropology of Consciousness, 23(1), 6-27. doi:https://doi.org/10.1111/j.1556-3537.2012.01054.x

George, E. W. (2010). Intangible cultural heritage, ownership, copyrights, and tourism. International Journal of Culture, Tourism and Hospitality Research, 4(4), 376-388. doi:https://doi.org/10.1108/17506181011081541

Gertner, R. K. (2019). The impact of cultural appropriation on destination image, tourism, and hospitality. Thunderbird International Business Review, 61(6), 873-877. doi:https://doi.org/10.1002/tie.22068

Gorman, P. (2006). A primer on shamanism. Retrieved from https://bit.1y/2ZhnwNz

Gorman, P. (2007). In case any of you decide to join a trip of mine. Retrieved from https://bit. ly/2BPSap8

Gorman, P. (2010a). Ayahuasca in my blood: 25 years of medicine dreaming. Vancouver, Canada: Gorman Bench Press.

Gorman, P. (2010b). The most wonderful mess. Retrieved from https://bit.1y/2VvgPqh

Gorman, P. (2010c). Shamanism and its possible effects on the world. Retrieved from https://bit.1y/2NXVT71

Gorman, P. (2015). Another fine mess you've gotten us into, ollie......the gorman blog. Retrieved from https://bit.ly/ 2YZD2id

Gorman, P. (2018a). Shift of perspective. Retrieved from https://bit.ly/2Ddque0

Gorman, P. (2018b). Tired of stupid. Retrieved from https://bit.ly/31M4t0f

Gorman, P. (2019). Reminded of fear. Retrieved from https://bit.ly/3eHKPH3

Kavenská, V., \& Simonová, H. (2015). Ayahuasca tourism: Participants in shamanic rituals and their personality styles, motivation, benefits and risks. Journal of Psychoactive Drugs, 47(5), 351-359. doi:https://doi.org/10.1080/02791072 .2015 .1094590

Luna, L. E. (1984). The healing practices of a peruvian shaman. Journal of Ethnopharmacology, 11(2), 123-133. doi:https:// doi.org/10.1016/0378-8741(84)90035-7

Murtagh, W. M. (2018). Cultural appropriation' is complicated when you're a mixed race chef passing as white makes my life easier at times, but to some people, it also delegitimizes my qualifications to cook Chinese food. Retrieved from https://bit.1y/2BmFUN3

Neill, S. J. (2006). Grounded theory sampling: The contribution of reflexivity. Journal of research in Nursing, 11(3), 253-260. doi:https://doi.org/10.1177/1744987106051850

Nelson, G. L. (2004). Writing and being: Taking back our lives through the power of language. Novato, CA: Inner Ocean Pub.

Ratner, C. (2002). Subjectivity and objectivity in qualitative methodology. In Forum Qualitative Sozialforschung/Forum: Qualitative Social Research, California, CA.

Re, T., Palma, J., Martins, J. E., \& Simões, M. (2016). Transcultual perspective on consciousness: Traditional use of ayahuasca in psychiatry in the 21st century in the Western world. Cosmos and History: The Journal of Natural and Social Philosophy, 12(2), 237-249.

Schlosser, L., Lyons, H., Talleyrand, R., Kim, B., \& Johnson, W. (2007). Advisor-advisee relationship in counseling psychology doctoral programs: A multiculturally-infused model. Journal of Career Development, 38(1), 44-61. doi:https://doi.org/ $10.1177 / 0894845309359286$

Trichter, S. (2010). Ayahuasca beyond the amazon the benefits and risks of a spreading tradition. Journal of Transpersonal Psychology, 42(2), 56-70. 